\title{
Katerina Seraïdari, La ville, la nation et l'immigré. Rapports entre Grecs et Turcs à Bruxelles
}

Paris, L'Harmattan, coll. « Compétences Interculturelles », 2012, 218 p.

Maixant Mebiame Zomo

\section{(2) OpenEdition}

\section{Journals}

Édition électronique

URL : http://journals.openedition.org/assr/26556

DOI : 10.4000 /assr.26556

ISSN : $1777-5825$

Éditeur

Éditions de l'EHESS

Édition imprimée

Date de publication : 31 décembre 2014

Pagination : 287

ISBN : 978-2-7132-2467-6

ISSN : 0335-5985

Référence électronique

Maixant Mebiame Zomo, « Katerina Seraïdari, La ville, la nation et l'immigré. Rapports entre Grecs et Turcs à Bruxelles », Archives de sciences sociales des religions [En ligne], 168 | 2014, mis en ligne le 21 mai 2015, consulté le 22 septembre 2020. URL : http://journals.openedition.org/assr/26556 ; DOI : https://doi.org/10.4000/assr.26556

Ce document a été généré automatiquement le 22 septembre 2020

(C) Archives de sciences sociales des religions 


\section{Katerina Seraïdari, La ville, la nation et l'immigré. Rapports entre Grecs et Turcs à Bruxelles}

Paris, L'Harmattan, coll. « Compétences Interculturelles », 2012, 218 p.

Maixant Mebiame Zomo

\section{RÉFÉRENCE}

Katerina Seraïdari, La ville, la nation et l'immigré. Rapports entre Grecs et Turcs à Bruxelles, Paris, L'Harmattan, coll. « Compétences Interculturelles », 2012, 218 p. 
1 Ville «puissante", selon la formule de Jean Beaufays dans Petite histoire d'un État binational, Bruxelles renferme plusieurs institutions européennes, est considéré comme un centre mondial de presse et de lobbying et cristallise autour d'elle de nombreux questionnements sociologique, anthropologique et identitaire. Dans le même temps, elle est aussi la capitale de la Belgique, possède une autonomie régionale, et constitue un des points de dispute entre francophones et néerlandophones, puisqu'il s'agit aussi de la capitale de la Flandre. C'est fort de ce constat sur la singularité de la ville de Bruxelles en Europe que Katerina Seraïdari nous livre une réflexion stimulante sur la ville, la nation et l'immigré.

La ville, la nation et l'immigré

Rapports entre Grecs et Turcs à Bruxelles
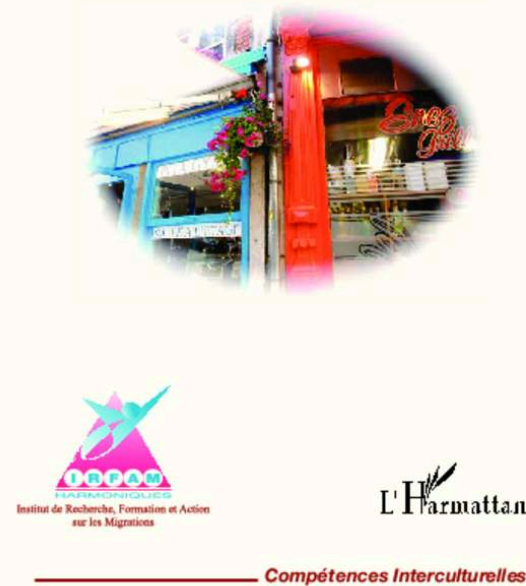

2 Ces trois concepts centraux sont abondamment discutés dès l'introduction qui, du point de vue théorique, renseigne énormément le lecteur. Et pour mieux rendre compte des rapports entre ces trois concepts, l'auteur va s'appuyer sur les résultats d'une étude menée sur les relations entre les communautés grecque et turque de Bruxelles. Deux groupes issus de l'immigration qui neutralisent ou réactivent des conflits géopolitiques autres comme les différends gréco-turcs. En tant qu'acteurs sociaux définis par un rapport particulier au territoire, les immigrés grecs et turcs exercent leurs influences dans les zones à géométrie variable : le quartier, la ville mais aussi l'État-nation, voire l'Union européenne dans son ensemble. Pris dans le mouvement, mais aussi initiateurs de processus d'enracinement, les immigrés permettent d'interroger les logiques de l'immobilité qui assignent à ces «régions morales » une hypothétique homogénéité et continuité.

En s'appuyant sur les outils méthodologiques de l'anthropologie sociale, l'auteur a effectué des entretiens semi-directifs avec des Turcs et Grecs, des récits de vie et des observations réalisées durant des manifestations et fêtes dans lesquelles participaient des membres de ces deux communautés.

Après de nombreux entretiens et observations de la vie quotidienne (quartiers, entreprises, liaisons amoureuses, commerce, alimentation, etc.) des Turcs et des Grecs, l'auteur identifie trois postures comportementales qui permettent de saisir les rapports entre ces deux communautés : affinité, confrontation et indifférence. Ces postures sont régies par le principe de réciprocité et constituent tant des auto que des hétérodéfinitions. Chaque discours produit des discours spécifiques et des variantes de l'Histoire nationale, ainsi qu'une série de pratiques. De ce point, certains marqueurs identitaires produisent, selon les interlocuteurs et la posture choisie, tant de l'affinité, de la distanciation que de la confrontation. L'auteur révèle et démontre justement que les stratégies identitaires des acteurs sociaux et la manière dont ils manipulent ces éléments d'appartenance qui ne sont ni des caractéristiques « innées » ni une fatalité 
(être Grec ou Turc) ni un but à atteindre (devenir belge), mais des ressources culturelles à mobiliser.

5 Les rapports d'affinité reposent moins sur des convictions (les deux peuples partagent les mêmes traits culturels) que sur un sentiment de nécessité (les deux groupes subissent les mêmes rejets et les mêmes difficultés dans un nouvel environnement). Comme le rappelle Katerina Seraïdari, «les Grecs et les Turcs étaient unis, car ils étaient tous deux "étrangers" dans un pays étranger » (p. 200). Les Grecs de Grèce et les Turcs de Turquie ne partagent pas les mêmes codes culturels tandis que ceux ou celles qui émigrent en Belgique se rapprochent et tissent des liens de solidarité. Dans les régions minières par exemple, les Grecs vont initier les mineurs turcs, joueront le rôle d'interprète et d'intermédiaire et ont su transformer les réseaux de solidarité en réseaux clientélistes. Les Turcs vont fréquenter en premiers les cafés grecs. Sur le plan de l'emploi, l'auteur rappelle aussi qu'à Bruxelles, l'expérience des Grecs dans le commerce, les taxis, la restauration, le cinéma, etc. est élément de rapprochement. Les Grecs vont par exemple diffuser les films turcs dans leur cinéma. Les deux autres postures comportementales sont la confrontation où on traite l'Autre comme un ennemi, ayant la certitude que celui-ci partage cet avis. La posture d'indifférence présuppose simplement des interactions conventionnelles entre personnes « civilisées » et courtoises.

D'autres acteurs extérieurs au conflit gréco-turc influencent aussi les rapports entre ces deux communautés. En effet, les Belges (en tant qu'employeurs, collègues, clients ou membres d'associations grecques), les Européens (comme spectateurs extérieurs ou comme collègues depuis les mines jusqu'aux institutions européennes), mais aussi les autres groupes ethniques habitant Bruxelles. Certaines postures comportementales comme l'affinité avec ces communautés deviennent comme des habitus qui s'expriment par des automatismes (se servir dans le frigo d'une amie grecque, tenir la cigarette de telle manière). L'auteur montre par ailleurs que l'analyse de ces petits gestes quotidiens révèle l'existence d'une identité "incorporée» (embodied). C'est, entre autres paramètres, par cette gestuelle (souvent considérée comme anecdotique) que les immigrés construisent leur relation à la nation : le fait de laisser la cuillère dans une tasse de thé ou de méprendre un pain turc pour un mouchoir suffit pour définir le champ d'altérité et d'affinité. Quant à leur rapport à la ville, il est défini par l'introduction des marqueurs dans l'espace (noms des commerces, appellations familiales des uns et des quartiers) mais aussi par une prise en charge du patrimoine local. Ces immigrés qui sont tiraillés par la dynamique du changement et la sécurité que l'appartenance confère, inscrivent la ville et la nation dans le champ relationnel et agonistique d'auto et d'hétérodéfinitions. Leur fonction par rapport à l'espace habité de la ville et de l'espace imaginé de la nation est «instituante» au sens où l'entend Castoriadis (L'institution imaginaire de la société).

7 En définitive, osons utiliser le mot : il s'agit d'un beau livre, qui nous séduit du début à la fin, de par la richesse et la finesse des données ethnographiques, la clarté de son écriture et la rigueur de la démonstration. 